\title{
Approximations to seismic AVA responses: Validity and potential in glaciological applications
}

\author{
Adam D. Booth ${ }^{1}$, Ezgi Emir ${ }^{2}$, and Anja Diez ${ }^{3}$
}

\begin{abstract}
Amplitude-variation-with-angle (AVA) methods establish the seismic properties of material either side of a reflective interface, and their use is growing in glaciology. The AVA response of an interface is defined by the complex Knott-Zoeppritz (K-Z) equations, numerous approximations to which we typically assume weak interface contrasts and isotropic propagation, inconsistent with the strong contrasts at glacier beds and the vertically transverse isotropic (VTI) fabrics were associated with englacial reflectivity. We considered the validity of a suite of approximate $\mathrm{K}-\mathrm{Z}$ equations for the exact $\mathrm{P}$-wave reflectivity $R_{\mathrm{P}}$ of ice overlying bedrock, sediment and water, and englacial interfaces
\end{abstract}

between isotropic and VTI ice. We found that the approximations of Aki-Richards, Shuey, and Fatti match exact glacier bed reflectivity to within $R_{\mathrm{P}} \pm 0.05$, smaller than the uncertainty in typical glaciological AVA analyses, but only for maximum incident angle $\theta_{i}$ limited to $30^{\circ}$. A stricter limit of $\theta_{i} \leq 20^{\circ}$ offered comparable accuracy to a hydrocarbon benchmark case of shale overlying gas-charged sand. The VTI-compliant Rüger approximation accurately described englacial reflectivity, to within $R_{\mathrm{P}} \pm 0.01$, and it can be modified to give a quadratic expression in $\sin ^{2}\left(\theta_{i}\right)$ suitable for curve-matching operations. Having shown the circumstances under which AVA approximations were valid for glaciological applications, we have suggested that their interpretative advantages can be exploited in the future AVA interpretations.

\section{INTRODUCTION}

Amplitude-variation-with-angle (AVA) analysis of seismic data is a key element in a growing number of glaciological research campaigns, in which it has been applied to characterize the properties of material in the subglacial environment. The AVA analysis describes the reflectivity of an interface as a function of the angle at which seismic energy is incident upon it. Thus, it provides insight into the material contrast (e.g., in seismic velocity, acoustic impedance, Poisson's ratio) either side of the interface (Aki and Richards, 1980). As such, AVA has been usefully applied to determine the hydrological condition of subglacial sediment beneath ice masses (Nolan and Echelmeyer, 1999), including the Greenland and Antarctic ice sheets (e.g., Anandakrishnan, 2003; Peters et al., 2007; Booth et al., 2012; Dow et al., 2013), to identify Antarctic subglacial lakes (Peters et al., 2008), and to interpret ice crystal orientation fabric (COF) from anisotropic seismic reflectivity (Horgan et al.,
2011). The term amplitude variation with offset (AVO) is often used instead of AVA, but the difference is simply that AVO characterizes reflectivity in terms of the offset between seismic source and geophone, rather than the incident angle (with an accurate velocity: depth function, the offset and angle are interchangeable).

An AVA response can be interpreted in absolute terms if some form of calibration between reflection coefficient and recorded seismic amplitude (influenced by reflectivity, e.g., damping, geometric spreading, scattering) can be defined. Glaciological drilling provides only a point sample of the glacier bed and/or a 1D distribution of englacial quantities (Truffer and Harrison, 2006; Lüthi et al., 2002; Gusmeroli et al., 2012; Andrews et al., 2014) and is logistically challenging (Siegert et al., 2014); hence, seismic campaigns seldom benefit from borehole observations. Approaches have therefore been developed to calibrate the reflectivity from aspects of the seismic data set alone, including estimating the initial amplitude of

Manuscript received by the Editor 19 March 2015; revised manuscript received 12 May 2015; published online 26 August 2015.

${ }^{1}$ Formerly Imperial College London, Department of Earth Science and Engineering, South Kensington Campus, London, UK; presently University of Leeds, School of Earth and Environment, Leeds, UK. E-mail: a.booth@imperial.ac.uk.

${ }^{2}$ Turkish Petroleum Corporation, Ankara, Turkey. E-mail: eemir@tpao.gov.tr.

${ }^{3}$ Formerly Alfred-Wegener-Institut Helmholtz-Zentrum für Polar- und Meeresforschung, Bremerhaven, Germany; presently University of California San Diego, Integrative Oceanography Division, Scripps Institution of Oceanography, California, USA. E-mail: adiez@ucsd.edu

(C) 2015 Society of Exploration Geophysicists. All rights reserved. 
the seismic source wavelet via energy-loss relationships (Peters et al., 2008; Horgan et al., 2011) and constraining reflectivity by comparing the amplitude of primary and multiple arrivals (Smith, 1997; King et al., 2003; Booth et al., 2012). However, such approaches can be problematic when applied to data with a low signal-to-noise ratio $(\mathrm{S} / \mathrm{N})$ because this can occur when geophones and seismic sources are located on (or close to) a bare ice surface (Dow et al., 2013).

The reliance on accurate calibration significantly hinders glaciological AVA interpretation, and interpretations could be assisted using methods developed in the hydrocarbon industry. Here, although well logs are usually available to calibrate reflectivity (Armstrong et al., 1995), the standard practice is to characterize and report AVA responses according to a simplified classification strategy (e.g., Rutherford and Williams, 1989; Castagna and Swan, 1997). Although the reflectivity of an interface is described exactly by the Knott-Zoeppritz (K-Z) equations (Aki and Richards, 1980), these are not intuitively interpreted (Chopra and Castagna, 2014), and reflectivity is more routinely described using parameters derived from AVA approximations to the K-Z equations. Such approximations make several assumptions about the reflectivity of an interface and typically require that the seismic contrast across it is small. Hydrocarbon-type interfaces (e.g., horizons between layers of fluid-filled clastic sediment) typically honor this assumption but ice, a highvelocity/low-density material, often has a strong seismic contrast with subglacial material. Approximate AVA methods show promise in glaciology, for characterizing reflectivity (Horgan et al., 2011; Diez and Eisen, 2015) or as the basis of extended interpretation schemes (Booth and Emir, 2014), but there has been little a priori investigation into their validity for cases of glaciological reflectivity. It is therefore unclear whether approximations developed for application in the hydrocarbon setting can be directly imported into glaciology, and so methods to mitigate the detrimental effects of a high-contrast interface may be required.

In this article, we test the validity of standard AVA approximations for characterizing the seismic reflectivity of glacier-bed and englacial interfaces, and we consider the potential to derive an approximation specific to glaciological cases. For glacier-bed reflectivity, we apply the approximations of Aki and Richards (1980), a)

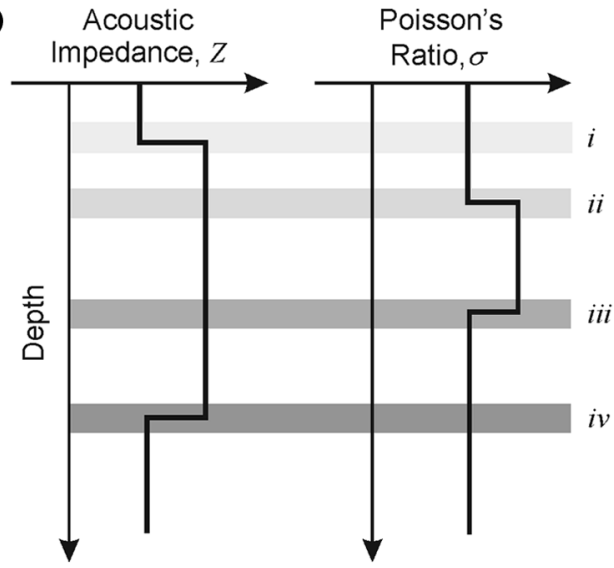

b)

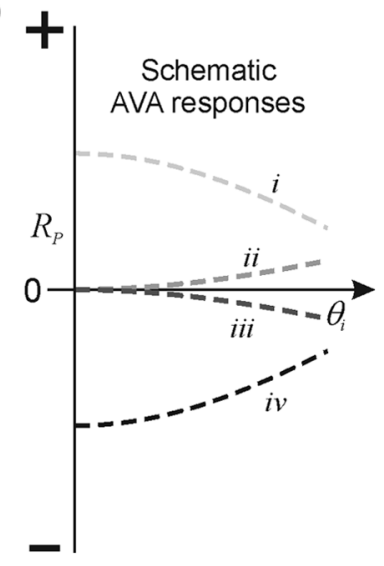

Figure 1. Schematic diagram of AVA responses, assuming boundaries that represent contrasts in either acoustic impedance or Poisson's ratio. (a) Vertical distributions of acoustic impedance and Poisson's ratio. Gray bands labeled i-iv represent positions in depth of seismic reflectors. (b) Schematic AVA responses showing the variation $R_{\mathrm{P}}$ with $\theta_{i}$, for reflectors $\mathrm{i}-\mathrm{iv}$.
Shuey (1985), Smith and Gidlow (1987), Wang (1999), and Fatti (1994), and the anisotropic approximation of Rüger (1976) is considered for englacial reflectivity. Peters et al. (2008) report that the uncertainty in typical seismic estimates of reflectivity is \pm 0.05 , given present-day data quality, and this criterion is used to appraise the accuracy of AVA approximations (Diez and Eisen, 2015). The approximations of Aki and Richards (1980) and Shuey (1985) predict exact reflectivity well but require a stricter maximum incident angle than would be advisable in the hydrocarbon setting $\left(20^{\circ}\right.$, compared to $30^{\circ}$ ). The physical contrast across a typical englacial horizon is small, and the approximation of Rüger (2002) is valid in glaciological applications. The potential variability of the glacierbed interface impedes the definition of an ice-specific AVA approximation, although a simple modification of the Rüger (2002) equation provides a simple means of evaluating the best-fit match to absolute englacial reflectivity. With these analyses, we have shown that AVA approximations are a useful basis for the continued development of AVA analysis in glaciology.

\section{REFLECTIVITY AND THE KNOTT-ZOEPPRITZ EQUATIONS}

The K-Z equations describe how seismic energy is reflected, transmitted, and partitioned into compressional (P-) and shear (S-) components on incidence at an interface (e.g., Aki and Richards, 1980). Reflectivity is governed by contrasts in $\mathrm{P}$-wave velocity $V_{\mathrm{P}}, \mathrm{S}$-wave velocity $V_{\mathrm{S}}$, density $\rho$, and the angle of incidence $\theta_{i}$. At normal incidence (i.e., $\theta_{i}=0^{\circ}$ ), the P-wave reflection coefficient $R_{\mathrm{P}}$ depends on contrasts in acoustic impedance, $Z$ (the product of $\rho$ and $V_{\mathrm{P}}$ ); contrasts in Poisson's ratio $\sigma$ also influence reflectivity at oblique incidence. An AVA response therefore records the variation in $R_{\mathrm{P}}$ with $\theta_{i}$. Because $\theta_{i}$ can be constrained with reference to a velocity: depth model (and is hence prone to any errors in measuring velocity), AVA analysis seeks to interpret the observed variation in reflection coefficient in terms of the physical properties either side of an interface.

If acoustic impedance increases across an interface (e.g., an iceover-bedrock case), $R_{\mathrm{P}}$ is positive at $\theta_{i}=0$ (Figure 1 , interface $i$ ); if Poisson's ratio increases (e.g., an ice-over-water case), $R_{\mathrm{P}}$ tends toward positive reflectivity $\theta_{i}$ (Figure 1, interface ii), at least up to the critical angle of incidence and for the range of acoustic impedance contrasts we consider here. Sensitivity to such mechanical properties has led to the broad adoption of AVA in the hydrocarbon industry, particularly for characterizing and monitoring the fluid (e.g., gas, oil and/or brine) component in hydrocarbon reservoirs (Fatti et al., 1994; Castagna and Swan, 1997; Landrø, 2001). An equivalent potential has been recognized for glaciological applications; hence, AVA analysis has been adopted into glaciological seismic research campaigns.

\section{Approximations to the Knott-Zoeppritz equations}

The complicated $\mathrm{K}-\mathrm{Z}$ equations do not support an intuitive interpretation of the physical properties that underlie the AVA response (Chopra and 
Castagna, 2014). Consequently, the K-Z equations are usually simplified according to linear or quadratic approximations (Aki and Richards, 1980; Shuey, 1985; Smith and Gidlow, 1987; Rüger, 1997; Fatti et al., 1994; Wang, 1999). For the linear cases, the AVA curve is described by just two coefficients: the intercept $I$ and gradient $G$ of a straight line. The interpretative benefits of such simplification include the following:

1) Crossplots of $I$ and $G$, which allow trends and variations within a set of AVA observations to be visualized (Castagna and Swan, 1997).

2) The definition of an AVA classification scheme that predicts the likely character of a reflective interface from relative variations in reflectivity (Rutherford and Williams, 1989; Castagna and Swan, 1997).

3) Attributes derived from $I$ and $G$ can be diagnostic indicators of variations in fluid-related properties, including porosity, pressure, and saturation (Fatti et al., 1994; Connolly, 1999; Landrø, 2001).

We consider six "industry-standard" approximations to the K-Z equations, assessing the assumptions in each and the suitability for glaciological applications. We first describe the approximation of Aki and Richards (1980), on which most of the other simplifications are based; thereafter, we consider the approximations of Shuey (1985), Smith and Gidlow (1987), Wang (1999) (the relevant equations are shown in Appendix A), Fatti et al. (1994), and Rüger (1997).

\section{Aki-Richards approximation}

Aki and Richards (1980) develop initial simplifications of the K-Z equations (Bortfeld, 1961; Richards and Frasier, 1976) and express P-wave reflectivity $R_{\mathrm{P}}\left(\theta_{A}\right)$ as a series of fractional velocity and density contrasts:

$$
R_{\mathrm{P}}^{\mathrm{AR}}\left(\theta_{A}\right)=A^{\mathrm{AR}} \frac{\Delta V_{\mathrm{P}}}{\overline{V_{\mathrm{P}}}}+B^{\mathrm{AR}} \frac{\Delta \rho}{\bar{\rho}}+C^{\mathrm{AR}} \frac{\Delta V_{\mathrm{S}}}{\overline{V_{\mathrm{S}}}},
$$

where $\Delta V_{\mathrm{P}}, \Delta V_{\mathrm{S}}$, and $\Delta \rho$ are the difference between quantities on either side of an interface, $\overline{V_{\mathrm{P}}}, \overline{V_{\mathrm{S}}}$, and $\bar{\rho}$ are the means of $V_{\mathrm{P}}, V_{\mathrm{S}}$, and $\rho$ on either side of the interface, and coefficients $A^{\mathrm{AR}}, B^{\mathrm{AR}}$, and $C^{\mathrm{AR}}$ are

$$
\begin{gathered}
A^{\mathrm{AR}}=\frac{1}{2}\left(1+\tan ^{2} \theta_{A}\right), \\
B^{\mathrm{AR}}=\frac{1}{2}-\left[\left(2{\overline{V_{\mathrm{S}}}}^{2} /{\overline{V_{\mathrm{P}}}}^{2}\right) \sin ^{2} \theta_{A}\right],
\end{gathered}
$$

and

$$
C^{\mathrm{AR}}=-\left(4{\overline{V_{\mathrm{S}}}}^{2} /{\overline{V_{\mathrm{P}}}}^{2}\right) \sin ^{2} \theta_{A} .
$$

The superscript AR denotes terms specific to the Aki-Richards approximation. The angle term $\theta_{A}$ is specifically the average of the incident and refracted angles, and not the incident angle itself. This is usually neglected in practice, and $\theta_{A}$ can be substituted with $\theta_{i}$ provided that velocity contrasts are weak and incident angles are small. For typical contrast magnitudes, the Aki-Richards approximation is valid for $\theta_{i} \leq 35^{\circ}$ (Aki and Richards, 1980; Chopra and Castagna, 2014), although stronger contrasts can invalidate it at smaller angles. Because most other AVA approximations derive from equation 1 , they inherit (and in some cases, add to) these underlying assumptions.

Aki and Richards (1980) rearrange equation 1 such that

$$
\begin{aligned}
& R_{\mathrm{P}}^{\mathrm{AR}}\left(\theta_{A}\right)=\frac{1}{2}\left[\frac{\Delta V_{\mathrm{P}}}{\overline{V_{\mathrm{P}}}}+\frac{\Delta \rho}{\bar{\rho}}\right] \\
& +\left[\frac{1}{2} \frac{\Delta V_{\mathrm{P}}}{\overline{V_{\mathrm{P}}}}-4 \frac{\bar{V}_{\mathrm{S}}^{2}}{{\overline{V_{\mathrm{P}}}}^{2}} \frac{\Delta V_{\mathrm{S}}}{\overline{V_{\mathrm{S}}}}-2 \frac{{\overline{V_{\mathrm{S}}}}^{2}}{{\overline{V_{\mathrm{P}}}}^{2}} \frac{\Delta \rho}{\bar{\rho}}\right] \sin ^{2} \theta_{A} \\
& +\frac{1}{2} \frac{\Delta V_{\mathrm{P}}}{\overline{V_{\mathrm{P}}}}\left(\tan ^{2} \theta_{A}-\sin ^{2} \theta_{A}\right),
\end{aligned}
$$

although the first term is often expressed as a fractional contrast in acoustic impedance, i.e., $\frac{1}{2} \frac{\Delta Z}{Z}$. The terms of equation 2 are grouped into coefficients to give the common form of the Aki-Richards expression:

$$
R_{\mathrm{P}}^{\mathrm{AR}}\left(\theta_{A}\right)=I^{\mathrm{AR}}+G^{\mathrm{AR}} \sin ^{2} \theta_{A}+C^{\mathrm{AR}}\left(\tan ^{2} \theta_{A}-\sin ^{2} \theta_{A}\right),
$$

where $I^{\mathrm{AR}}, G^{\mathrm{AR}}$, and $C^{\mathrm{AR}}$ are the intercept, gradient, and curvature, respectively, of a three-term fit to the $\mathrm{K}-\mathrm{Z}$ equations. Provided that the small-contrast criterion is honored, these terms yield quantitative information about velocity and density contrasts across the interface. For small angles, the third term of equation 2 is negligible $\left(\tan ^{2} \theta_{A} \approx \sin ^{2} \theta_{A}\right)$; hence, $C^{\mathrm{AR}}$ is often neglected and the most common form of the Aki-Richards approximation is linear with $\sin ^{2} \theta_{A}$. In later analysis, we consider the relative accuracy of the two- and three-term Aki-Richards approximations.

\section{Shuey approximation}

Shuey's approximation to the K-Z equations (Shuey, 1985) simplifies the Aki-Richards approximation in equation 2 by replacing the $V_{\mathrm{S}}$ terms with contrasts in Poisson's ratio. Once rearranged, the common form of the Shuey approximation is identical to the linear simplification of equation $3: \mathrm{s}$

$$
R_{\mathrm{P}}^{\mathrm{S}}\left(q_{A}\right)=I^{\mathrm{S}}+G^{\mathrm{S}} \sin ^{2} \theta_{A},
$$

although with different definitions of the intercept $I^{S}$ and gradient $G^{\mathrm{S}}$ terms (Appendix equation A-1). Superscript $\mathrm{S}$ denotes terms specific to the Shuey approximation. The Shuey coefficients are the usual foundation of AVA crossplots (Simm et al., 2000) and classification schemes (Castagna and Swan, 1997) applied in industries. Although small contrasts between density and P-wave velocity are still required, no assumption is made for the Poisson's ratio contrast (Shuey, 1985).

\section{Smith-Gidlow approximation}

Although Shuey (1985) remove the explicit dependency on $V_{\mathrm{S}}$ from equation 2, Smith and Gidlow (1987) invoke Gardner's relation (Gardner et al., 1974) to remove the explicit control of density. Gardner's relation is an empirical law for brine-saturated sedimentary rock, which states that $\rho \propto V_{\mathrm{P}}^{0.25}$. Smith and Gidlow (1987) show that 


$$
\frac{\Delta \rho}{\bar{\rho}}=\frac{1}{4} \frac{\Delta V_{\mathrm{P}}}{\overline{V_{\mathrm{P}}}},
$$

thereby allowing equation 2 to be expressed in terms of $V_{\mathrm{P}}$ and $V_{\mathrm{S}}$ only as

$$
R_{\mathrm{P}}^{\mathrm{SG}}\left(\theta_{A}\right)=C^{\mathrm{SG}}\left[\frac{\Delta V_{\mathrm{P}}}{\overline{V_{\mathrm{P}}}}\right]+D^{\mathrm{SG}}\left[\frac{\Delta V_{\mathrm{S}}}{\overline{V_{\mathrm{S}}}}\right],
$$

where SG denotes terms specific to the Smith-Gidlow approximation, and terms $C^{\mathrm{SG}}$ and $D^{\mathrm{SG}}$ are defined in equations $\mathrm{A}-2 \mathrm{a}$ and A-2b. Because P- and S-wave velocities show different sensitivities in contrasts to rock versus fluid changes, attributes derived from the Smith-Gidlow approximation (e.g., the "fluid factor"; Fatti et al., 1994) have applications as indicators of fluid saturation.

\section{Wang approximation}

Wang's (1999) approximation (equation A-3) is a three-term quadratic expression for $R_{\mathrm{P}}$ and also invokes Gardner's relation, and the extra degree of freedom in the expression matches exact AVA across a larger $\theta_{A}$ range (Wang, 1999). Wang's (1999) approximation states

$$
\begin{gathered}
R_{\mathrm{P}}^{\mathrm{WA}}\left(\theta_{A}\right)=A^{\mathrm{WA}} \frac{\Delta V_{\mathrm{P}}}{\overline{V_{\mathrm{P}}}}+B^{\mathrm{WA}} \frac{\Delta V_{\mathrm{S}}}{\overline{V_{\mathrm{S}}}} \\
+C^{\mathrm{WA}}\left(\frac{1}{4} \frac{\Delta V_{\mathrm{P}}}{\overline{V_{\mathrm{P}}}}+2 \frac{\Delta V_{\mathrm{S}}}{\overline{V_{\mathrm{S}}}}\right)^{2},
\end{gathered}
$$

where WA denotes terms specific to Wang's (1999) approximation, and terms $A^{\mathrm{WA}}, B^{\mathrm{WA}}$, and $C^{\mathrm{WA}}$ are given in equations $\mathrm{A}-3 \mathrm{a}, \mathrm{A}-3 \mathrm{~b}$, and A-3c, respectively. Attributes derived from the coefficients of Wang's (1999) approximation also have applications as indicators of pore fluid properties (Negrete Cadena and Booth, 2014).

\section{Fatti approximation}

Fatti et al. (1994) rearrange equation 2 in terms of acoustic impedance and shear impedance, $Y$ (the product of $V_{\mathrm{S}}$ and $\rho$ ) to define the reflectivity as

$$
\begin{aligned}
R_{\mathrm{P}}^{F}\left(\theta_{A}\right)= & \frac{1}{2}\left(1+\tan ^{2} \theta_{A}\right) \frac{\Delta Z}{\bar{Z}}-4\left(\frac{\overline{V_{\mathrm{S}}}}{\overline{V_{\mathrm{P}}}}\right)^{2} \sin ^{2} \theta_{A} \frac{\Delta Y}{\bar{Y}} \\
& -\left[\frac{1}{2} \tan ^{2} \theta_{A}-2\left(\overline{\overline{V_{\mathrm{S}}}}\right)^{2} \sin ^{2} \theta_{A}\right] \frac{\Delta \rho}{\bar{\rho}},
\end{aligned}
$$

Table 1. Summary of assumptions and limitations of K-Z approximations considered in this paper (Wang, 1999; Chopra and Castagna, 2014). Here, $\theta_{i}$ represents the largest angle for which the approximations are considered valid, for the typical seismic contrasts for which they are applied.

\begin{tabular}{lcc} 
Approximation & $\begin{array}{c}\text { Maximum } \\
\text { recommended } \theta_{i}\left({ }^{\circ}\right)\end{array}$ & Comment \\
\hline $\begin{array}{l}\text { Aki-Richards (Aki and Richards, 1980) } \\
\begin{array}{l}\text { Shuey (Shuey, 1985) } \\
\text { Smith-Gidlow (Smith and Gidlow, 1987) }\end{array}\end{array}$ & 35 & $\begin{array}{c}\text { Assumes } \theta_{A}=\theta_{i} \text {, and small velocity contrasts } \\
\text { Subcritical }\end{array}$ \\
Wang (Wang, 1999) & 40 & $\begin{array}{c}\text { Equivalent assumptions to Aki-Richards; } V_{\mathrm{S}} \text { expressed as } \\
\text { Equivalent assumptions to Aki-Richards. } \rho \text { expressed } \\
\text { as a fraction of } V_{\mathrm{P}} \text {, via Gardner's relation. }\end{array}$ \\
Fatti (Fatti et al., 1994) & Subcritical & $\begin{array}{c}\text { Equivalent assumptions to Aki-Richards. } \rho \text { expressed } \\
\text { as a fraction of } V_{\mathrm{P}} \text {, via Gardner's relation. }\end{array}$ \\
& & $\begin{array}{c}\text { Equivalent assumptions to Aki-Richards. Reflectivity } \\
\text { is a function of acoustic and shear impedance. }\end{array}$
\end{tabular}

Rüger (Rüger, 1997)

20

Equivalent assumptions to Aki-Richards. Accommodates weak VTI fabric.

Table 2. Seismic velocities, densities, Poisson's ratios $(\sigma)$ and acoustic and shear impedances $(Z$, and $Y$, respectively) of materials used in AVA models. Glaciological cases from Peters et al. (2008) and hydrocarbons case from Rüger (2002). These are expressed as fractional contrasts in Table 4.

Glaciological cases

Hydrocarbon case

\begin{tabular}{ccccccccc} 
& & Ice & Bedrock & Lithified sediment & Dilatant sediment & Water & Shale & Gas sand \\
\hline \multirow{2}{*}{ Seismic quantity } & $V_{\mathrm{P}}(\mathrm{m} / \mathrm{s})$ & 3810 & 5200 & 3750 & 1700 & 1498 & 2730 & 2020 \\
& $V_{\mathrm{S}}(\mathrm{m} / \mathrm{s})$ & 1860 & 2800 & 2450 & 200 & 0 & 1240 & 1230 \\
& $\rho\left(\mathrm{kg} / \mathrm{m}^{3}\right)$ & 920 & 2700 & 2450 & 1800 & 1000 & 2350 & 2130 \\
& $\sigma$ & 0.344 & 0.296 & 0.128 & 0.493 & 0.500 & 0.370 & 0.205 \\
& $Z\left(\times 10^{6} \mathrm{~g} / \mathrm{m}^{2} \mathrm{~s}\right)$ & 3.50 & 14.04 & 9.19 & 3.06 & 1.50 & 6.42 & 4.30 \\
& $Y\left(\times 10^{6} \mathrm{~g} / \mathrm{m}^{2} \mathrm{~s}\right)$ & 1.71 & 7.56 & 6.00 & 0.36 & 0 & 2.91 & 2.62 \\
\hline
\end{tabular}


where superscript $F$ denotes reflectivity specific to the Fatti approximation. Fatti et al. (1994) make no assumptions about velocity or density contrast. Although inferences from the Fatti approximation are often used alongside terms derived from the SmithGidlow equation, its explicit control on density requires no implicit conformity to Gardner's relation.

\section{Rüger approximation}

The previous approximations assume isotropic propagation, whereas that of Rüger (1997) honors propagation in material with a weak vertical transverse isotropy (VTI). An expression for the exact $R_{\mathrm{P}}$ in VTI cases is given by Graebner (1992) and Rüger (2002); Rüger's approximation, denoted by superscript $R$, to this is

$$
\begin{gathered}
R_{\mathrm{P}}^{R}\left(\theta_{A}\right)=\frac{1}{2} \frac{\Delta Z}{\bar{Z}}+\frac{1}{2}\left[\frac{\Delta V_{\mathrm{P}}}{\overline{V_{\mathrm{P}}}}-\left(\frac{2 \overline{V_{\mathrm{S}}}}{\overline{V_{\mathrm{P}}}}\right)^{2} \frac{\Delta \mu}{\bar{\mu}}+\Delta \delta\right] \sin ^{2} \theta_{A} \\
+\frac{1}{2}\left[\frac{\Delta V_{\mathrm{P}}}{\overline{V_{\mathrm{P}}}}+\Delta \epsilon\right] \sin ^{2} \theta_{A} \tan ^{2} \theta_{A},
\end{gathered}
$$

where $\mu$ is the shear modulus $\left(=\rho V_{\mathrm{S}}^{2}\right), \delta$ and $\varepsilon$ are the Thomsen anisotropy parameters (Thomsen, 1986), and all velocities are measured in the vertical direction. The approximation requires incident angle to be restricted to $\theta_{i} \leq 20^{\circ}$ (Rüger, 1997). The inclusion of VTI terms makes the Rüger approximation appropriate for characterizing englacial reflectivity, which is intrinsically related to anisotropy variations (Diez and Eisen, 2015). The terms in the Rüger approximation can be grouped into coefficients, similar to the Aki-Richards equation, such that

$$
R_{\mathrm{P}}^{R}\left(\theta_{A}\right)=I^{R}+G^{R} \sin ^{2} \theta_{A}+C^{R} \sin ^{2} \theta_{A} \tan ^{2} \theta_{A} .
$$

The assumptions and limitations involved with each approximation are summarized in Table 1. We now consider the accuracy for simulated cases of glaciological reflectivity.

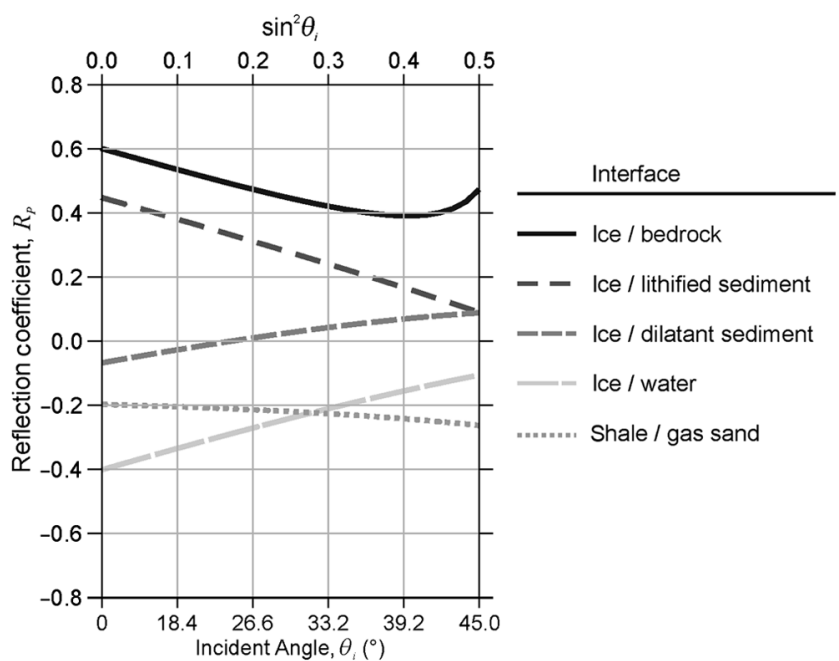

Figure 2. The exact AVA responses for P-waves reflected from glacier-bed interfaces and a representative hydrocarbon case (quantities in Table 2); $R_{\mathrm{P}}$ is plotted against $\sin ^{2}\left(\theta_{i}\right)$, and $\theta_{i}$ is shown on the lower axis for reference.

\section{REFLECTIVITY MODELING}

\section{Glacier bed reflectivity}

We model the P-wave reflectivity for glacier-bed examples using the Consortium for Research in Elastic Wave Exploration Seismology (CREWES, University of Calgary) formulation of the KZequations. The parameters used to model glacier bed reflectivity are listed in Table 2 (Peters et al., 2008), and we consider $R_{\mathrm{P}}$ for ice overlying bedrock, lithified and dilatant sediment, and water. The term "dilatant" is consistent with the terminology of Peters et al. (2008) and implies weak sediment with a high water content, rather

Table 3. Elastic moduli for isotropic and VTI ice, expressed in units of GPa in Voigt notation (Voigt, 1910) and corresponding Thomsen parameters $\delta$ and $\epsilon$ (Thomsen, 1986). Moduli $C_{33}=C_{22}, C_{12}=C_{21}, C_{13}=C_{31}$, and $C_{44}=C_{55}$; all other elements are 0 .

\begin{tabular}{lccc}
\hline Elastic modulus & $\begin{array}{c}\text { Isotropic ice } \\
\left(\mathrm{COA}=90^{\circ}\right)\end{array}$ & $\begin{array}{c}\text { VTI ice } \\
\left(\mathrm{COA}=0^{\circ}\right)\end{array}$ & $\begin{array}{c}\text { VTI ice } \\
\left(\mathrm{COA}=40^{\circ}\right)\end{array}$ \\
\hline$C_{11}(\mathrm{GPa})$ & 13.79 & 13.93 & 13.69 \\
$C_{33}(\mathrm{GPa})$ & 13.79 & 15.01 & 14.26 \\
$C_{12}(\mathrm{GPa})$ & 6.19 & 7.08 & 6.91 \\
$C_{13}(\mathrm{GPa})$ & 6.19 & 5.77 & 6.16 \\
$C_{44}(\mathrm{GPa})$ & 3.80 & 3.01 & 3.34 \\
$C_{66}(\mathrm{GPa})$ & 3.80 & 3.42 & 3.39 \\
$\epsilon$ & 0.00 & -0.04 & -0.02 \\
$\delta$ & 0.00 & -0.19 & -0.09 \\
\hline
\end{tabular}

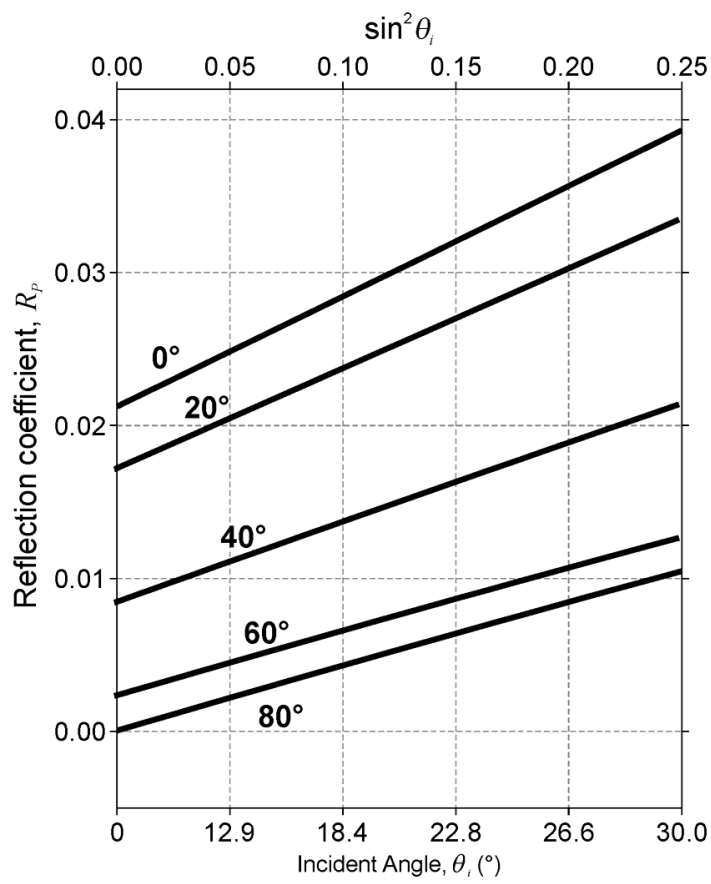

Figure 3. Exact AVA responses for englacial reflectivity (Rüger, 2002), for the interface between isotropic and VTI ice, with COA increased from $0^{\circ}$ to $80^{\circ}$. 
than sediment undergoing a particular mechanical process. We also model $R_{\mathrm{P}}$ for a representative hydrocarbon case, here the interface between shale and a gas-charged sand (Rüger, 2002; Table 2), to benchmark the accuracy of the AVA approximations in glaciology against the style of reflectivity for which they are valid and routine.

Reflectivity is modeled for incident angles of $\theta_{i} \leq 45^{\circ}$. Larger angles would be superfluous because no AVA approximation is deemed accurate beyond this threshold. All angles are subcritical at each interface; hence, the inaccuracies in the $\mathrm{K}-\mathrm{Z}$ equations at near-critical angles (van der Baan and Smit, 2006) are not important; however, this would only be relevant for the ice/bedrock interface, across which there is a velocity increase. All interfaces are assumed to be the welded horizontal and planar (on the scale of the seismic wavelength) contact between two homogeneous, isotropic half-spaces. Although deep ice can have a strong VTI fabric (e.g., Gow and Meese, 2007), Diez and Eisen (2015) show that the anisotropic contribution to basal reflectivity is negligible; hence, anisotropy is neglected at this stage of analysis but is revisited in the following section.

The modeled AVA responses are shown in Figure 2. Here, $R_{\mathrm{P}}$ is plotted against $\sin ^{2}\left(\theta_{A}\right)$ such that the fit between model AVA curves and the linearized approximations (e.g., Aki-Richards and Shuey) is more easily appreciated in later figures than with an axis of $\theta_{i}$.

\section{Englacial reflectivity}

Englacial reflections arise from changes in the orientation fabric of anisotropic ice crystals. Stresses within an ice mass cause ice
Figure 4. P-wave reflectivity as defined by approximations to the K-Z equations, for ice overlying (a) bedrock, (b) lithified sediment, (c) dilatant sediment and (d) water, and (e) the hydrocarbon benchmark of shale overlying gas sand. a)

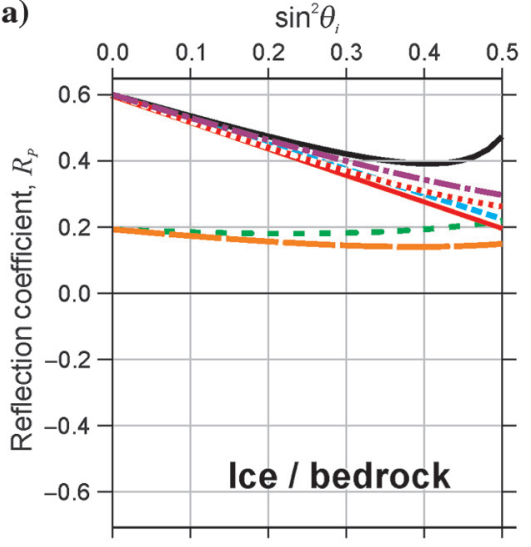

c)

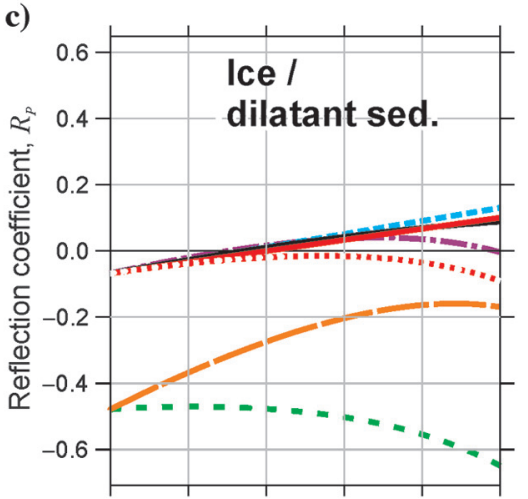

e)

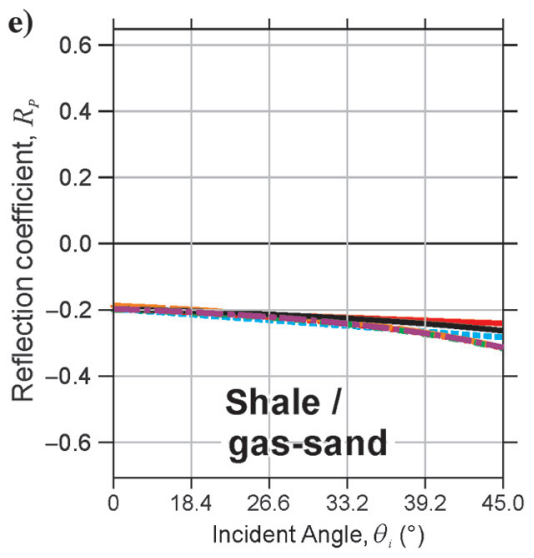

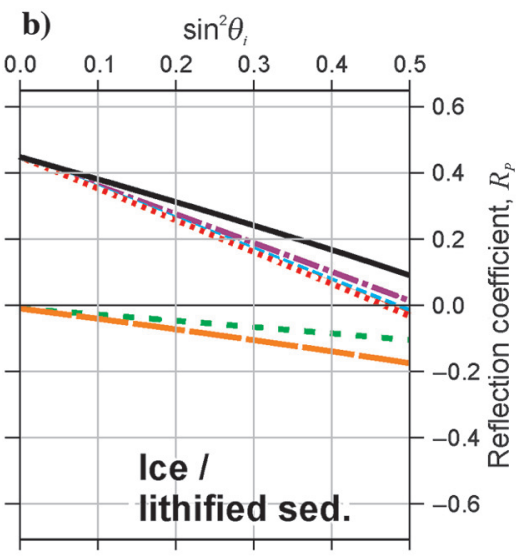

d)

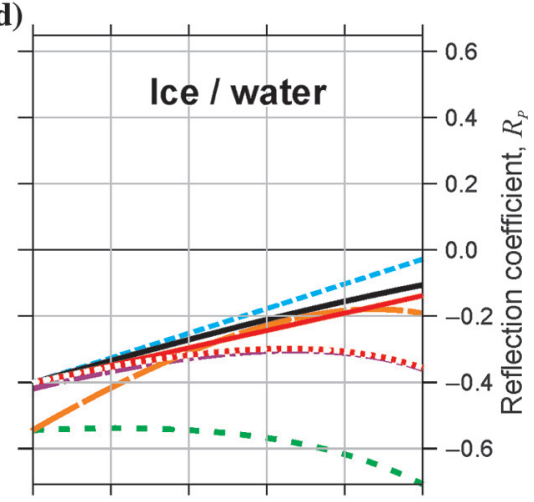

K-Z (exact)

Aki-Richards (two-term)

Aki-Richards (three-term)

Shuey

Smith-Gidlow

Wang

Fatti 
crystals to align, thereby clustering the direction of their fast-propagation axes. The greater the intensity of clustering, the greater the VTI in the macroscopic ice mass (Diez and Eisen, 2015). Cluster intensity is described by the cone-opening angle (COA) (Pettit et al., 2011; Diez and Eisen, 2015), and a small COA describes strongly aligned ice crystals. The AVA approximations for characterizing englacial reflectivity should therefore honor VTI.

The P-wave reflectivity was modeled using the exact reflectivity expression of Rüger (2002), for the interface between isotropic ice $\left(\mathrm{COA}=90^{\circ}\right)$ and varying intensities of VTI ice (COA increased from $0^{\circ}$ to $80^{\circ}$ ). The ice density is fixed at $920 \mathrm{~kg} / \mathrm{m}^{3}$ throughout. We calculated the elasticity tensors for each ice case using the tensor

Table 4. Quantities listed in Table 2, expressed as a fractional contrast across the reflective interface. The upper layer is assumed to be ice in all glaciological cases; the upper and lower layers are shale and gas-sand, respectively, in the hydrocarbon case.

Glaciological cases

Hydrocarbon case

Bedrock Lithified sediment Dilatant sediment Water

\begin{tabular}{|c|c|c|c|c|c|c|}
\hline \multirow[t]{6}{*}{ Contrast } & $\frac{\Delta V_{\mathrm{P}}}{\bar{V}}$ & 0.31 & -0.02 & -0.77 & -0.87 & -0.30 \\
\hline & $\frac{\Delta V_{S}}{\overline{V_{S}}}$ & 0.40 & 0.27 & -1.61 & -2.00 & -0.01 \\
\hline & $\frac{\Delta \rho}{\bar{\rho}}$ & 0.98 & 0.91 & 0.65 & 0.08 & -0.10 \\
\hline & $\frac{\Delta \sigma}{\bar{\sigma}}$ & -0.15 & -0.92 & 0.36 & 0.37 & -0.57 \\
\hline & $\frac{\Delta Z}{\bar{Z}}$ & 1.20 & 0.90 & -0.13 & -0.80 & -0.40 \\
\hline & $\frac{\Delta Y}{\bar{Y}}$ & 1.26 & 1.11 & -1.30 & -2.00 & -0.11 \\
\hline
\end{tabular}

a)

b)
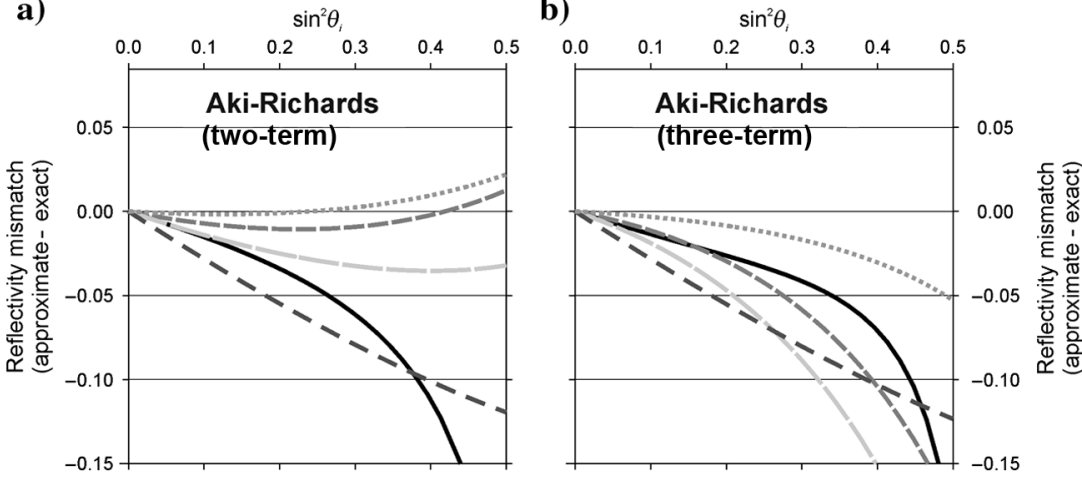

c)

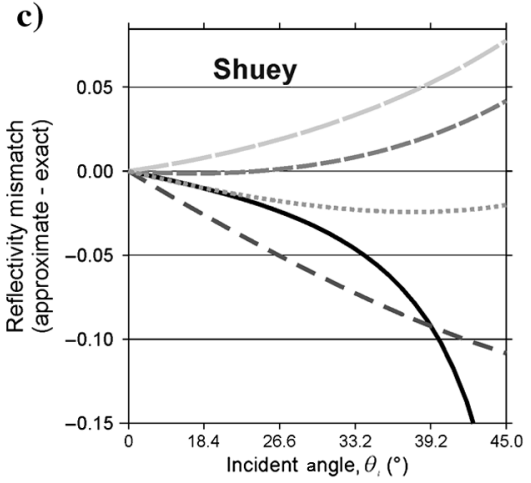

d)

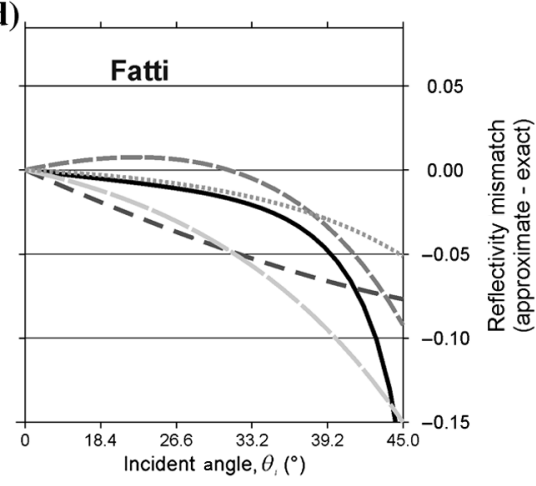

- Ice / bedrock $\quad-$ Ice / dilat
- Ice / lithified sediment - Ice / wate

...... Shale/gas sand measured by Gammon et al. (1983), averaged over the specific COA (Diez and Eisen, 2015). Table 3 shows elastic moduli for isotropic ice, and for moderately and intensely fabricated VTI ice (COA of $0^{\circ}$ and $40^{\circ}$, respectively). Reflectivity is calculated for $\theta_{i} \leq 30^{\circ}$ (Figure 3 ) to show the impact of violating the $20^{\circ}$ criterion established by Rüger (1997).

\section{ACCURACY OF AMPLITUDE-VARIATION-WITH- ANGLE APPROXIMATIONS}

Glacier bed scenarios

Figure 4 shows the exact and approximate AVA responses for glacier-bed cases and the hydrocarbon benchmark. All approximations perform well for the hydrocarbon benchmark, but only the Aki-Richards, Shuey, and Fatti models show potential in glacier bed cases. The poor performance of the Smith-Gidlow and Wang approximations is attributed to their assumption of Gardner's relation. As shown in equation 4, Gardner's relation requires that velocity contrasts across an interface have the same polarity as density contrasts. Table 4 shows interface properties expressed as fractional contrasts. Velocity and density contrasts show the same polarity in the hydrocarbon example, but these are opposite in the glaciological cases. Consequently, the SmithGidlow and Wang approximations are invalid for

Figure 5. Mismatch between the exact and approximate AVA curves, as defined by the (a) two-term Aki-Richards, (b) three-term Aki-Richards, (c) Shuey, and (d) Fatti approximations, for the reflectivity cases in Figure 4. Negative values imply that the approximate case underestimates the exact case. 
glaciological reflectivity and are not considered further in this analysis.

Mismatches between approximate and exact AVA curves are shown in Figure 5, for the remaining models. Although all models faithfully predict $R_{\mathrm{P}}$ at $\theta_{i}=0^{\circ}$, the mismatch grows with $\theta_{i}$ as the assumption $\theta_{A}=\theta_{i}$ breaks down. Across the full range of $\theta_{i}$, the mismatch is never greater than $R_{\mathrm{P}} \pm 0.05$ for the hydrocarbon benchmark but exceeds $R_{\mathrm{P}}(-0.15,+0.05)$ in most glaciological cases. The violation of $\theta_{A}=\theta_{i}$ is typically exacerbated in glaciological cases by strong $V_{\mathrm{P}}$ contrasts (Table 4 ), but strong contrasts in $V_{\mathrm{S}}$ and $\rho$ also contribute to the mismatch. Consistent with recommendations in Table 1, the Fatti approximation offers the best accuracy across the largest $\theta_{i}$ range. For the Aki-Richards models, the three-term approximation is

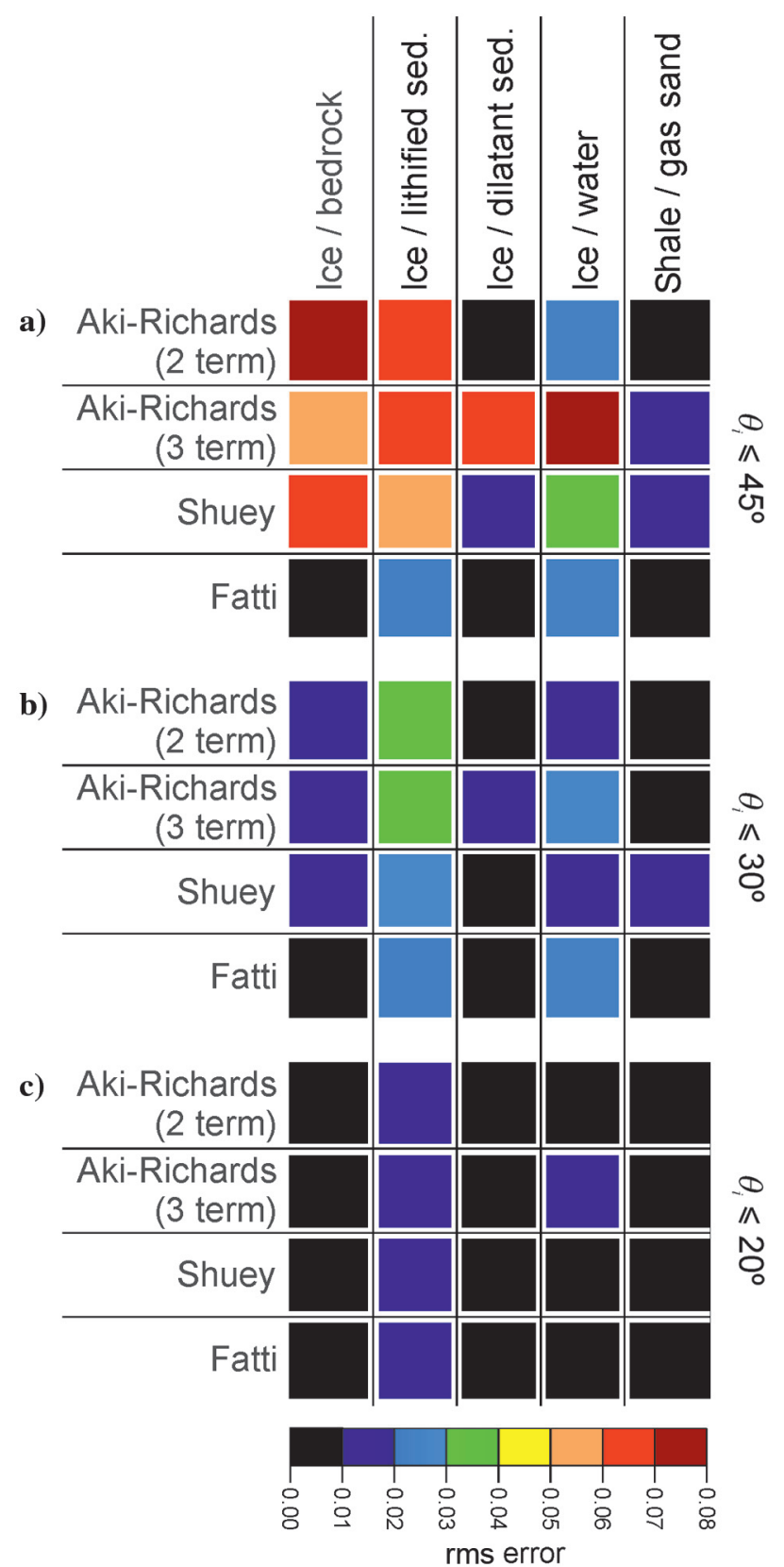

Figure 6. Mismatch in Figure 5, expressed as an rms error across a range for $\theta_{i}$ of (a) $0^{\circ}-45^{\circ}$, (b) $0^{\circ}-30^{\circ}$, and (c) $0^{\circ}-20^{\circ}$. typically less accurate than the two term (compare Figure 5a and 5b, particularly at large $\theta_{i}$ ). The third term of this expression depends only on $V_{\mathrm{P}}$ (equation 2); therefore, the impact of the large $V_{\mathrm{P}}$ contrast is exaggerated in the three-term approximation. Indeed, the influence of $V_{\mathrm{P}}$ on the Aki-Richards approximations is highlighted by the similarity of the ice/lithified sediment responses in Figure 5a and 5b: This interface has $V_{\mathrm{P}}$ negligible contrast in $(-0.02$, smaller than the hydrocarbon example); hence, the curves predicted by the two- and three-term expressions are indistinguishable. The Shuey approximation performs similarly to the Aki-Richards approximations, although it has a tendency to overestimate rather than to underestimate the reflectivity.

AVA approximations are conventionally deemed accurate if $\theta_{i} \leq 35^{\circ}$ (Table 1), although we suggest restricting this angle for glaciological applications. By mitigating the detrimental impact of large seismic contrasts, glacier-bed AVA could be amenable to a similar suite of analysis routines as applied to hydrocarbon-style interfaces (e.g., Castagna and Swan, 1997; Booth and Emir, 2014). Figure 6 shows the root-mean-square (rms) error between exact and approximate AVA curves for (1) $\theta_{i} \leq 45^{\circ}$ (i.e., the whole range in Figure 5), (2) $\theta_{i} \leq 30^{\circ}$, and (3) $\theta_{i} \leq 20^{\circ}$. In Figure $6 \mathrm{~b}$, the accuracy for the glaciological cases is brought within $R_{\mathrm{P}} \pm 0.05$, the typical threshold of error in present-day glacier-bed AVA surveys (Diez and Eisen, 2015), although errors remain more significant than for the hydrocarbon case. Imposing a stricter angle limit (Figure $6 \mathrm{c}$ ) reduces the remaining error in the glaciological cases to within $R_{\mathrm{P}} \pm 0.02$, comparable throughout to the hydrocarbon example. Therefore, we suggest that approximations of glacier-bed reflectivity should consider a maximum $\theta_{i}$ of $30^{\circ}$, with a reduction to $20^{\circ}$ considered if extended analysis routines are required.

\section{Englacial reflectivity}

Figure 7a shows the match between the exact AVA curves and those defined by the Rüger (1997) approximation. Small contrast assumptions are more valid for englacial reflectivity than for a glacier bed: There is no density change, and the velocity contrast between isotropic and intensely fabricated ice is only approximately $6 \%$. The match between the exact AVA curves and those defined by the Rüger approximation is strong. The approximated reflectivity is consistently accurate at normal incidence, but errors increase monotonically with angle (Figure 7b) to a mismatch of approximately -0.008 at $\theta_{i}=30^{\circ}$ for the strongest COF transitions. At $\theta_{i}=20^{\circ}$, the maximum recommended by Rüger (1997), the approximation is always within $15 \%$ of $R_{\mathrm{P}}$.

With respect to the terms in equation 9, trends in these errors suggest that $I^{R}$ and $C^{R}$ are particularly accurate, and the bulk of the mismatch arises instead from underestimating $G^{R}$. On comparison with its definition in equation $8, G^{R}$ is the only term that is dependent on $V_{\mathrm{S}}$; hence, errors will most likely arise from the misrepresentation of elastic properties. The Rüger approximation will therefore yield $V_{\mathrm{P}}$ contrasts more accurately than $V_{\mathrm{S}}$, although the mismatch is nonetheless small compared to the inherent noise level in estimates of $R_{\mathrm{P}}$.

\section{DISCUSSION}

\section{Toward an ice-specific amplitude-variation-with-angle approximation}

Industry-standard approximations to the $\mathrm{K}-\mathrm{Z}$ equations show the potential for application in glaciological analyses although not 
without a more restrictive set of acquisition and analysis criteria. Furthermore, full exploitation of these approximations may require additional constraint of seismic properties (e.g., $V_{\mathrm{S}}$, to inform shear impedance in the Fatti approximation); hence, we support continued development of glaciological borehole (Gusmeroli et al., 2012; Diez and Eisen, 2015) and/or S-wave (Polom et al., 2014) techniques. However, characterizing glaciological reflectivity with an ice-specific AVA approximation (rather than one defined for clastic sediment) may allow limitations on $\theta_{i}$ to be relaxed and could provide a basis for crossplots and extended attribute analysis (e.g., Booth and Emir, 2014).

For the glacier-bed case, the definition of a generalized AVA expression is likely to be problematic. Although the seismic properties of ice are relatively predictable (Kohnen, 1972, 1974), the variability of $V_{\mathrm{P}}, V_{\mathrm{S}}$, and $\rho$ in the subglacial environment (Table 2) is large and not easily predicted. It may be possible to define empirical relationships for specific subclasses of material (e.g., types of subglacial sediment), but this requires laboratory calibration and a priori information about the expected subglacial environment. Consequently, we suggest that the AkiRichards, Shuey, and Fatti AVA approximations already provide as generalized a reflectivity model as possible. Furthermore, the simplicity of the two-term Aki-Richards and Shuey approximations make them suitable for curve-fitting sets of arbitrary AVA observations, as linear functions of $\sin ^{2} \theta_{A}$.

This simplicity is considered in a proposed modification to the Rüger approximation, to make it amenable to curve fitting for cases of englacial reflectivity. Horgan et al. (2011) apply the Aki-Richards approximation to characterize englacial reflectivity; yet, a fitting algorithm based on the Rüger approximation would be more appropriate given the underlying compatibility with VTI transitions. The Rüger and Aki-Richards approximations are already similar (compare equations 3 and $10)$, but the third term of the Rüger approximation varies as $\sin ^{2} \theta_{A} \tan ^{2} \theta_{A}$. This term can be equated to $\sin ^{4} \theta_{A}$ provided that the small-angle criterion is honored (i.e., $\theta_{i} \leq 20^{\circ}$, across which the maximum difference in $\sin ^{4} \theta_{A}$ and $\sin ^{2} \theta_{A} \tan ^{2} \theta_{A}$ is approximately $12 \%$ ), allowing the Rüger approximation to be expressed as a quadratic relationship in $\sin ^{2} \theta_{A}$. Furthermore, density contrasts at englacial interfaces are negligible; hence, the first coefficient in equation 9 can be expressed in terms of $V_{\mathrm{P}}$ alone. Our modified version of the Rüger approximation $R_{\mathrm{P}}^{\mathrm{RM}}\left(\theta_{A}\right)$, is

$$
\begin{gathered}
R_{\mathrm{P}}^{\mathrm{RM}}\left(\theta_{A}\right)=\frac{1}{2} \frac{\Delta V_{\mathrm{P}}}{\overline{V_{\mathrm{P}}}}+\frac{1}{2}\left[\frac{\Delta V_{\mathrm{P}}}{\overline{V_{\mathrm{P}}}}-\left(\frac{2 \overline{V_{\mathrm{S}}}}{\overline{V_{\mathrm{P}}}}\right)^{2} \frac{\Delta \mu}{\bar{\mu}}+\Delta \delta\right] \sin ^{2} \theta_{A} \\
+\frac{1}{2}\left[\frac{\Delta V_{\mathrm{P}}}{\overline{V_{\mathrm{P}}}}+\Delta \epsilon\right] \sin ^{4} \theta_{A},
\end{gathered}
$$

which simplifies to

$$
R_{\mathrm{P}}^{\mathrm{RM}}\left(\theta_{A}\right)=I^{\mathrm{RM}}+G^{\mathrm{RM}} \sin ^{2} \theta_{A}+C^{\mathrm{RM}} \sin ^{4} \theta_{A} .
$$

The difference between $R_{\mathrm{P}}$ predicted by equations 9 and 11 is negligible up to $40^{\circ}$, but it rapidly increases thereafter (Figure 8).
However, there is no significant difference between either version of the Rüger approximation across the recommended angle range of $0 \leq \theta_{i} \leq 20^{\circ}$.

The terms of equation 12 are also amenable to crossplotting. Figure 9 shows the reflections in Figure 3 expressed on a three-term crossplot, derived from fitting equation 12. Summarizing each AVA curve in terms of three coefficients allows trends and differences between them to be easily visualized (and it is certainly preferable to overlaying many AVA curves). For example, the crossplot shows that $I^{\mathrm{RM}}$ decreases with the VTI contrast across the interface, but also that $C^{\mathrm{RM}}$ becomes increasingly negative. By comparing ratios between the three coefficients with reference values, an estimate of the contrast underlying any observed englacial reflection can be made. Importantly, the magnitude and polarity of each coefficient scale linearly with the amplitude of the seismic wavelet; therefore,
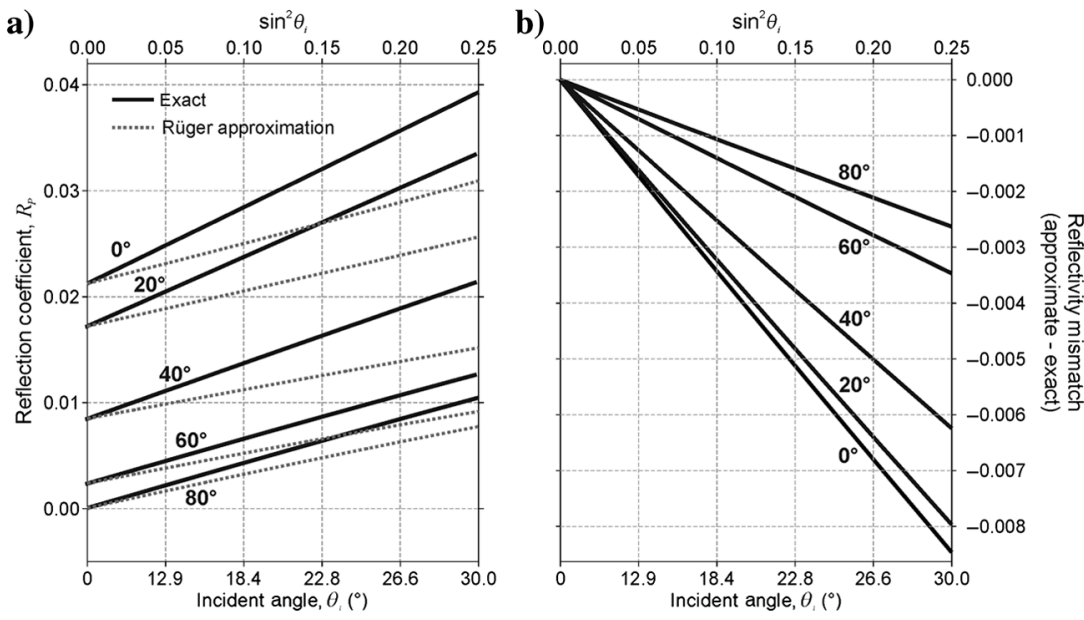

Figure 7. Match between the exact englacial reflectivity and that defined by the Rüger approximation; for examples, see Figure 3. (a) Mismatch grows with increasing $\theta_{i}$ and decreasing COA. (b) Mismatch between approximate and exact reflectivity models. For $\theta_{i}<20^{\circ}$, the approximate $R_{\mathrm{P}}$ is never more imprecise than -0.005 .

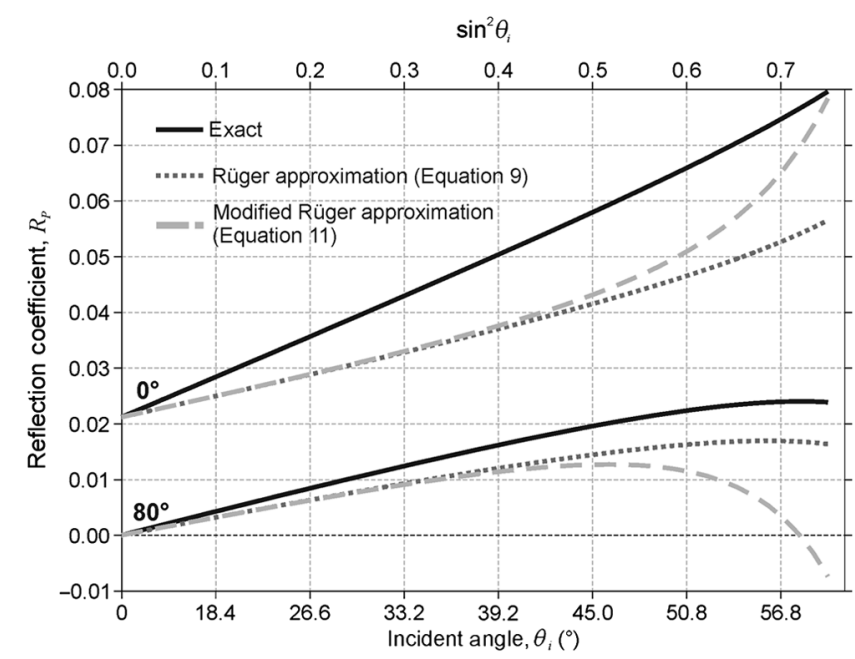

Figure 8. Match between englacial reflectivity (solid line), the Rüger approximation in equation 9 (dotted), and the modified Rüger approximation in equation 11 (dashed). The trial range of $\theta_{i}$ is extended to $60^{\circ}$ to emphasize the inaccuracies in the approximations. For clarity, only the extreme cases of englacial reflectivity are shown. 


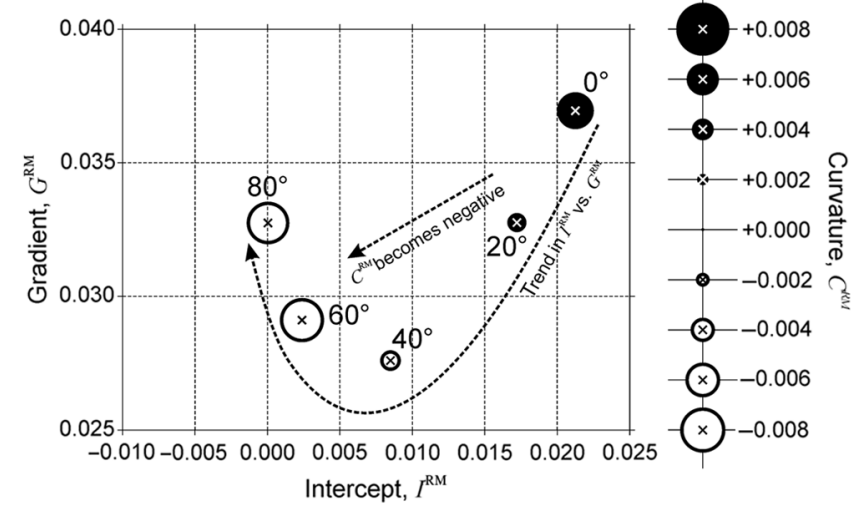

Figure 9. Example AVA crossplot for englacial reflectivities shown in Figure 3, based on coefficients of the modified Rüger approximation in equation 12 . The magnitude and polarity of curvature $C^{\mathrm{RM}}$ is shown by the symbol size and black/white variation, respectively.

equivalent trends would be observed whether the AVA response was considered in calibrated or uncalibrated terms. When absolute reflectivity is a desirable goal in seismic analysis, crossplots such as Figure 9 provide a powerful interpretative aid if AVA interpretation could only be performed in relative terms.

\section{CONCLUSIONS}

The definition of absolute seismic reflectivity is the goal of many AVA investigations in glaciology, although there are interpretative benefits of characterizing reflectivity from approximate AVA curves. These benefits may be particularly powerful for data with a low $\mathrm{S} / \mathrm{N}$, but in any case, they provide an extended set of analysis options. Approximate AVA equations can be applied to glaciological styles of reflectivity but because of the potential magnitude of seismic contrast, only when the incident angle $\theta_{i}$ is limited to $20^{\circ}$. Under such conditions, the Aki-Richards, Shuey, and Fatti approximations suitably characterize the AVA response of a range of glacier bed interfaces, with the Aki-Richards and Shuey models suitable for curve-fitting arbitrary AVA observations as linear functions of $\sin ^{2} \theta_{i}$. The VTI-compliant Rüger approximation provides a good match across a range of englacial reflectivities and is adapted to provide a three-term fitting algorithm suitable for characterizing AVA trends at englacial interfaces. Having demonstrated the conditions under which AVA approximations are valid in glaciology, we recommend their continued development in this setting as a seismic analysis tool.

\section{ACKNOWLEDGMENTS}

E. Emir was funded by the Turkish Petroleum Corporation during her study at Imperial College London's M.S. petroleum geophysics programme. A. Diez was funded with the "Emmy Noether" project grant EI 672/5 provided to O. Eisen and later by National Science Foundation project no. PLR-1246151. We thank the CREWES Consortium for access to the modeling code and P. F. Daley for advice with MATLAB scripts. This manuscript was greatly improved with constructive comments from S. Arcone, A. Cherrett, and an anonymous third reviewer.

\section{APPENDIX A}

\section{EQUATIONS FOR AMPLITUDE-VARIATION- WITH-ANGLE APPROXIMATIONS}

\section{Shuey approximation}

Shuey (1985) adapt the Aki-Richards approximation by removing the explicit influence of S-wave velocities and instead incorporating Poisson's ratio. The coefficient of $\sin ^{2} \theta_{A}$ in equation 2 was modified as

$$
\frac{1}{2}\left[\frac{\Delta V_{\mathrm{P}}}{\overline{V_{\mathrm{P}}}}+\frac{\Delta \rho}{\bar{\rho}}\right] A^{\mathrm{S}}+\frac{\Delta \sigma}{(1-\bar{\sigma})^{2}},
$$

where $\sigma$ is Poisson's ratio and

$$
A^{\mathrm{S}}=B^{\mathrm{S}}-2\left(1+B^{\mathrm{S}}\right) \frac{1-2 \bar{\sigma}_{2}}{1-\bar{\sigma}}
$$

with

$$
B^{\mathrm{S}}=\frac{\frac{\Delta V_{\mathrm{P}}}{\overline{V_{\mathrm{P}}}}}{\frac{\Delta V_{\mathrm{P}}}{\overline{V_{\mathrm{P}}}}-\frac{\Delta \rho}{\bar{\rho}}}
$$

where superscript S denotes the Shuey approximation.

\section{Smith-Gidlow approximation}

Substituting Gardner's relation in equation 4 into the AkiRichards approximation in equation 1 , and rearranging, gives

$$
R_{\mathrm{P}}^{\mathrm{SG}}\left(\theta_{A}\right)=C^{\mathrm{SG}}\left[\frac{\Delta V_{\mathrm{P}}}{\overline{V_{\mathrm{P}}}}\right]+D^{\mathrm{SG}}\left[\frac{\Delta V_{\mathrm{S}}}{\overline{V_{\mathrm{S}}}}\right],
$$

where

$$
C^{\mathrm{SG}}=\frac{5}{8}-\frac{1}{2} \frac{{\overline{V_{\mathrm{S}}}}^{2}}{{\overline{V_{\mathrm{P}}}}^{2}} \sin ^{2} \theta_{A}+\tan ^{2} \theta_{A}
$$

and

$$
D^{\mathrm{SG}}=-4 \frac{{\overline{V_{\mathrm{S}}}}^{2}}{{\overline{V_{\mathrm{P}}}}^{2}} \sin ^{2} \theta_{A}
$$

with superscripts SG denoting terms specific to the Smith-Gidlow approximation.

\section{Wang approximation}

Consistent with Smith and Gidlow (1987), Wang (1999) invokes Gardner's relation and expresses P-wave reflectivity as

$$
\begin{gathered}
R_{\mathrm{P}}^{\mathrm{WA}}\left(\theta_{A}\right)=A^{\mathrm{WA}} \frac{\Delta V_{\mathrm{P}}}{\overline{V_{\mathrm{P}}}}+B^{\mathrm{WA}} \frac{\Delta V_{\mathrm{S}}}{\overline{V_{\mathrm{S}}}} \\
+C^{\mathrm{WA}}\left(\frac{1}{4} \frac{\Delta V_{\mathrm{P}}}{\overline{V_{\mathrm{P}}}}+2 \frac{\Delta V_{\mathrm{S}}}{\overline{V_{\mathrm{S}}}}\right)^{2},
\end{gathered}
$$

where 


$$
\begin{gathered}
A^{\mathrm{WA}}=\frac{5}{8}+\frac{1}{2} \tan ^{2} \theta_{A}-\frac{1}{2} \frac{{\overline{V_{\mathrm{S}}}}^{2}}{{\overline{\mathrm{P}_{\mathrm{P}}}}^{2}} \sin ^{2} \theta_{A}, \\
B^{\mathrm{WA}}=-4 \frac{{\overline{V_{\mathrm{S}}}}^{2}}{{\overline{V_{\mathrm{P}}}}^{2}} \sin ^{2} \theta_{A},
\end{gathered}
$$

and

$$
C^{\mathrm{WA}}=\frac{{\overline{V_{\mathrm{S}}}}^{3}}{{\overline{V_{\mathrm{P}}}}^{3}} \cos \theta_{A} \sin ^{2} \theta_{A} .
$$

Superscripts WA denote the Wang approximation.

\section{REFERENCES}

Aki, K., and P. G. Richards, 1980, Quantitative seismology, theory and methods: Freeman.

Anandakrishnan, S., 2003, Dilatant till layer near the onset of streaming flow of ice stream C, determined by AVO analysis: Annals of Glaciology, 36 283-286, doi: 10.3189/172756403781816329.

Andrews, L. C., G. A. Catania, M. J. Hoffman, J. D. Gulley, M. P. Lüthi, C. Ryser, R. L. Hawley, and T. A. Neumann, 2014, Direct observations of evolving subglacial drainage beneath the Greenland Ice Sheet: Nature, 514, $80-83$.

Armstrong, P. N., W. Chmela, and W. S. Leany, 1995, AVO calibration using borehole data: First Break, 13, 319-328, doi: 10.3997/1365-2397.1995016.

Booth, A. D., R. A. Clark, B. Kulessa, T. Murray, J. Carter, S. Doyle, and A. Hubbard, 2012, Thin-layer effects in glaciological seismic amplitudeversus-angle (AVA) analysis: Implications for characterising a subglacia till unit, Russell Glacier, West Greenland: The Cryosphere, 6, 909-922.

Booth, A. D., and E. Emir, 2014, A classification scheme for glaciological AVA responses: Presented at AGU Fall Meeting.

Bortfeld, R., 1961, Approximations to the reflection and transmission coefficients of plane longitudinal and transverse waves: Geophysical Prospecting, 9, 485-502, doi: 10.1111/j.1365-2478.1961.tb01670.x.

Castagna, J. P., and H. W. Swan, 1997, Principles of AVO crossplotting: The Leading Edge, 16, 337-342, doi: 10.1190/1.1437626.

Chopra, S., and J. P. Castagna, 2014, AVO: SEG Investigations in Geophysics 16.

Connolly, P., 1999, Elastic impedance: The Leading Edge, 18, 438-452, doi: 10.1190/1.1438307.

Diez, A., and O. Eisen, 2015, Seismic wave propagation in anisotropic ice - Part 1: Elasticity tensor and derived quantities from ice-core properties: The Cryosphere, 9, 367-384, doi: 10.5194/tc-9-367-2015.

Dow, C. F., A. Hubbard, A. D. Booth, S. H. Doyle, A. Gusmeroli, and B. Kulessa, 2013, Seismic evidence of mechanically weak sediments underlying Russell Glacier, West Greenland: Annals of Glaciology, 54, 135141, doi: 10.3189/2013AoG64A032.

Fatti, J. L., G. C. Smith, P. J. Vail, P. J. Strauss, and P. R. Levitt, 1994, Detection of gas in sandstone reservoirs using AVO analysis: A 3-D seismic case history using the Geostack technique: Geophysics, 59, 1362-1376, doi: 10.1190/1.1443695.

Gammon, P. H., H. Kiefte, M. J. Cloiter, and W. W. Denner, 1983, Elastic constant of artificial and natural ice samples by Brillouin spectroscopy: Journal of Glaciology, 29, 433-460.

Gardner, G. H. F., L. W. Gardner, and A. R. Gregory, 1974, Formation velocity and density — The diagnostic basis for stratigraphic traps: Geophysics, 39, 770-780, doi: 10.1190/1.1440465.

Gow, A. J., and D. Meese, 2007, Physical properties, crystalline textures and c-axis fabrics of the Spile Dome (Antarctica) ice core: Journal of Glaciology, 53, 573-584, doi: 10.3189/002214307784409252.

Graebner, M., 1992, Plane-wave reflection and transmission coefficients for a transversely isotropic solid: Geophysics, 57, 1512-1519, doi: 10.1190/1 .1443219 .

Gusmeroli, A., E. C. Pettit, J. H. Kennedy, and C. Ritz, 2012, The crystal fabric of ice from full-waveform borehole sonic logging: Geophysical Research Letters, 117, F03021, doi: 10.1029/2012JF002343.

Horgan, H. J., S. Anandakrishnan, R. B. Alley, P. G. Burkett, and L. E. Peters, 2011, Englacial seismic reflectivity: Imaging crystal-orientation fabric in West Antarctica: Journal of Glaciology, 57, 639-650, doi: 10 .3189/002214311797409686.

King, E. C., A. M. Smith, T. Murray, and G. W. Stuart, 2003, Glacier-bed characteristics of midtre Lovénbreen, Svalbard, from high-resolution seismic and radar surveying: Journal of Glaciology, 54, 145-156, doi: 10 .3189/002214308784409099.

Kohnen, H., 1972, Über die Beziehung zwischen seismichen Geschwindigkeiten und der Dichte in Firn und Eis: Zeitschrift für Geophysik, 38, 925-935.

Kohnen, H., 1974, The temperature dependence of seismic waves in ice: Journal of Glaciology, 13, 144-147.

Landrø, M., 2001, Discrimination between pressure and fluid saturation changes from time-lapse seismic data: Geophysics, 66, 836-844, doi: 10.1190/1.1444973.

Lüthi, M., M. Funk, A. Iken, S. Gogenini, and M. Truffer, 2002, Mechanisms of fast flow in Jakobshavn Isbrae, West Greenland; part III: Measurements of ice deformation, temperature, and cross-borehole conductivity in boreholes to bedrock: Journal of Glaciology, 48, 369-385, doi: 10.3189/ 172756502781831322

Negrete Cadena, R., and A. D. Booth, 2014, AVA hydrocarbon indicator from least-squares inversion based on a quadratic form of Zoeppritz's equations: 76th EAGE Conference and Exhibition, EAGE, We E102 12

Nolan, M., and K. Echelmeyer, 1999, Seismic detection of transient changes beneath Black Rapids Glacier, U.S.A.: Part II. Basal morphology and processes: Journal of Glaciology, 45, 132-146.

Peters, L. E., S. Anandakrishnan, R. B. Alley, and A. M. Smith, 2007, Extensive storage of basal meltwater in the onset region of a major Wes Antarctic ice stream: Geology, 35, 251-254, doi: 10.1130/G23222A.1.

Peters, L. E., S. Anandakrishnan, C. W. Holland, H. J. Horgan, D. D. Blakenship, and D. E. Voigt, 2008, Seismic detection of a subglacial lake near South Pole, Antarctica: Geophysical Research Letters, 35, L23501, doi: 10.1029/2008GL035704.

Pettit, E. C., W. D. Waddington, T. Harrison, T. Thorsteinsson, D. Elsberg, J. Morack, and Z. A. Zumberge, 2011, The crossover stress anisotropy and ice flow law at Siple Dome, West Antarctica: Journal of Glaciology, 57, 39-52, doi: 10.3189/002214311795306619.

Polom, U., C. Hoefstede, A. Diez, and O. Eisen, 2014, First glacier-vibroseismic experiment - Results from cold firn of Colle Gnifetti: Near Surface Geophysics, 12, 493-504, doi: 10.3997/1873-0604.2013059.

Richards, P. G., and C. W. Frasier, 1976, Scattering of elastic wave from depth-dependent inhomogeneities: Geophysics, 41, 441-458, doi: 10 $.1190 / 1.1440625$.

Rüger, A., 1997, P-wave reflection coefficients for transversely isotropic models with vertical and horizontal axis of symmetry: Geophysics, 62 , 713-722, doi: 10.1190/1.1444181.

Rüger, A., 2002, Reflection coefficients and azimuthal AVO analysis in anisotropic media: SEG Geophysical Monograph Series 10.

Rutherford, S. R., and R. H. Williams, 1989, Amplitude-versus-offset variations in gas sands: Geophysics, 54, 680-688, doi: 10.1190/1.1442696.

Shuey, R. T., 1985, A simplification of the Zoeppritz equations: Geophysics 50, 609-614, doi: 10.1190/1.1441936.

Siegert, M. J., K. Makinson, D. Blake, M. Mowlem, and N. Ross, 2014, An assessment of deep hot-water drilling as a means to undertake direct measurement and sampling of Antarctic subglacial lakes: Experience and lessons learned from the Lake Ellsworth field season 2012/13: Annals of Glaciology, 55, 59-73, doi: 10.3189/2014AoG65A008.

Simm, R., R. White, and R. Uden, 2000, The anatomy of AVO crossplots: The Leading Edge, 19, 150-155, doi: 10.1190/1.1438557.

Smith, A. M., 1997, Basal conditions on Rutford Ice Stream, West Antarctica, from seismic observations: Journal of Geophysical Research, 102 543-552, doi: 10.1029/96JB02933.

Smith, G. C., and P. M. Gidlow, 1987, Weighted stack for rock property estimation and detection of gas: Geophysical Prospecting, 35, 9931014, doi: 10.1111/j.1365-2478.1987.tb00856.x.

Thomsen, L., 1986, Weak elastic anisotropy: Geophysics, 51, 1954-1966, doi: 10.1190/1.1442051.

Truffer, M., and W. D. Harrison, 2006, In situ measurements for till deformation and water pressure: Journal of Glaciology, 52, 175-182, doi: 10 .3189/172756506781828700.

Van der Baan, M., and D. Smit, 2006, Amplitude analysis of isotropic pwave reflections: Geophysics, 71, no. 6, C93-C103, doi: 10.1190/1 .2335877.

Voigt, W., 1910, Lehrbuch der Kristallphysik (mit Ausschluss der Kristalloptik): Bibliotheca Mathematica Teubneriana - Johnson.

Wang, Y., 1999, Approximations to the Zoeppritz equations and the use in AVO analysis: Geophysics, 64, 1920-1927, doi: 10.1190/1.1444698. 